\title{
Para Ciro Flamarion Cardoso (1942-2013): uma homenagem de pesquisadores da América lusa escravista
}

\author{
João Fragoso* \\ Carla Maria de Almeida* \\ Luís Augusto Farinatti ${ }^{* * *}$
}

\section{NOTA EDITORIAL}

Ciro Flamarion Cardoso, falecido no último dia 29 de junho, foi membro do Conselho Editorial da Topoi. Revista de História desde sua fundação. Nos últimos tempos, Cardoso se dedicava cada vez mais à história antiga, porém é sempre bom lembrar seu papel na virada da historiografia brasileira com a sua maior profissionalização, segundo os critérios dos Annales: elaboração da história - problema através da combinação de teorias, métodos e fontes primárias. Esta ação ocorreu especialmente nos seus estudos e na sua docência em escravidáo e em história agrária, entre fins da década de 1960 e princípios dos anos de 1990. A seguir, as repercussóes de tal ação são ilustradas por meio dos depoimentos - em especial, das reincidências de testemunhos - de docentes de três geraçóes diferentes, no caso João Fragoso (doutor em 1990), Carla Almeida (doutora em 2001) e Luís Augusto Farinatti (doutor em 2007). 
Corria o ano de 1977, no Brasil prevalecia a ditadura militar, porém já existiam indícios de mudanças: os metalúrgicos do $\mathrm{ABC}$ paulista faziam greves, começavam as passeatas estudantis e na imprensa escrevia-se sobre uma possível distensão política. Neste ambiente, no Instituto de Filosofia e Ciências Sociais (IFCS) da Universidade Federal do Rio de Janeiro, travou-se uma conversa entre dois militantes do movimento estudantil: um aluno de história e um colega de outro curso. No início da conversa, ambos comentaram o texto que circulava pelo Instituto e que tinha o enigmático título Por que a direita não pensa. Em seguida, um virou para o outro e perguntou: "Por que você perde tempo indo aos Arquivos? Você já sabe qual será o resultado da sua pesquisa! O Brasil colonial foi um grande canavial subjugado aos interesses internacionais". Diante de tal afirmação, o aluno de história emudeceu e desconcertado começou a rir.

Cerca de dez anos antes de tal diálogo, em 1968, o Centro de Estudos e Pesquisas Marxistas, sediado em Paris, realizava um seminário chamado Sobre o Feudalismo e entre as contribuiçôes ao Dossier preparatório temos um texto de Ciro Cardoso. ${ }^{1}$ Publicado em francês em 1971 e em português em 1973. Nele, Ciro expunha as bases de sua hipótese de doutorado, qual seja: o eixo da dinâmica da América lusa colonial estava nas suas relaçóes sociais e, em especial, nas relaçôes de produção escravistas (diferentes da Antiguidade, pois aquelas eram "fortemente aristocráticas e paternalistas"). Com isto ele criticava o modelo explicativo proposto por Caio Prado Junior, dominante na esquerda brasileira, no seu movimento estudantil e, portanto, nas cabeças daqueles dois alunos do IFCS antes mencionados. Segundo este modelo, o Brasil colonial era capitalista, ideia de que Ciro Cardoso discordava, pois, entre outros problemas, tal concepçáo baseava-se em viajantes e cronistas de época e náo em fontes primárias dos arquivos de Portugal e do Brasil; arquivos na época geralmente frequentados por "historiadores interessados nas batalhas e no pitoresco". ${ }^{2}$ Outro problema consistia na excessiva atenção à circulação de mercadorias em detrimento da produção. Anos depois, a historiografia brasileira passava a dar mais atenção não só à dinâmica das relaçôes sociais de produção, mas também aos agentes de tais relaçôes/interaçóes: escravos, senhores, pardos, forros, índios, prostitutas, comerciantes retalhistas etc. Entendendo tais personagens como criadores de mercadorias, mas também da cultura, da política, dos sonhos e dos pesadelos da sociedade brasileira.

De volta ao Brasil em fins da década de 1970, Ciro Cardoso, já consagrado internacionalmente como especialista da escravidáo americana, comporia sob a tutela de Maria Yedda Linhares o grupo de História Agrária da Pós-Graduaçáo em História da Universidade Fede-

\footnotetext{
${ }^{1}$ Ciro Cardoso iniciou seu doutorado na Universidade de Paris X em 1967 sob a orientaçáo de Frédéric Mauro. Sua ida a Paris teve a intermediação de Maria Yedda Leite Linhares (professora catedrática da UFRJ, cassada pelo AI-5) que o conheceu, se não me engano, enquanto professor temporário no Departamento de História da UFRJ.

${ }^{2}$ CARDOSO, Ciro Flamarion S. Observações sobre o "Dossier" preparatório da discussão sobre o modo de produção feudal. In: CENTRE D’ÉTUDES ET RECHERCHES MARXISTES. Sobre o feudalismo. Lisboa: Editorial Estampa, 1973. p. 71-73.
} 
ral Fluminense. A influência de tal grupo na historiografia brasileira pode ser medida pelo fato de ele ter formado, nos anos de 1980, profissionais como Francisco Carlos Teixeira da Silva, Hebe Mattos, Manolo Florentino e Sheila de Castro Faria. Em outras palavras, tal grupo interferiu nos rumos da história econômica até à história política e dos estudos das elites até os da pós-abolição. (João Fragoso)

Falar em Ciro Cardoso é também inevitavelmente demarcar a inflexão ocorrida no final dos anos de 1970 e na década seguinte na historiografia brasileira sobre o período colonial. Suas reflexóes produziram uma necessária revisão nas explicaçôes correntes sobre a escravidão nas Américas e também sobre o estatuto das sociedades coloniais. Numa época em que o trânsito internacional dos historiadores brasileiros não era tão frequente como hoje, Ciro Cardoso circulou por várias instituiçóes europeias e latino-americanas o que o colocou em contato com métodos de pesquisa e preocupações comuns a outras tradiçóes historiográficas. Sobretudo sua ligação com pesquisadores latino-americanos ligados à compreensão da América hispânica e sua recusa em se ligar a um marxismo esquemático para a explicação da realidade colonial o conduziram a estar alerta para a necessidade de se observar a lógica interna das sociedades americanas e não reduzi-las a meros apêndices da economia europeia. Ciro Cardoso contribuiu para um novo modo de se refletir sobre o período colonial valorizando a lógica interna das sociedades americanas sem abrir mão de pensá-las integradas à dinâmica externa. A partir dessas proposiçóes genéricas, uma série de novas pesquisas produzidas, sobretudo nos programas de pós-graduação brasileiros, baseadas em corpus documentais até então não utilizados e com técnicas e métodos de pesquisa inovadores, demonstrou de modo irreversível a existência de uma dinâmica interna da sociedade colonial brasileira e demarcou a força do mercado interno na definição desta dinâmica. Também a presença fundamental da escravidão, não só nas áreas exportadoras como também em regióes ligadas ao mercado interno, teve destaque nas proposiçóes de Ciro Cardoso e ganhou relevo nesses novos estudos.

Aprofundando o que estas pesquisas realizadas entre os anos de 1980 e o final da década de 1990 revelaram, mais recentemente, o maior contato dos pesquisadores brasileiros com a historiografia portuguesa e europeia tem suscitado uma série de novos estudos cujo eixo central tem sido repensar a natureza da sociedade colonial brasileira, entendida não mais como um apêndice da metrópole, ou como uma realidade dotada de determinaçôes internas e por vezes apartada daquela, mas, sim, como uma região integrada ao vasto império português que tinha seus domínios estendidos desde a Índia e partes da China e Japão, passando pelo norte da África muçulmana e pelas costas ocidental e oriental africanas, até o território do Brasil. Desse modo, se, nos últimos anos, a reflexão sobre o período colonial tem caminhado para enfatizar a dinâmica do império português muito mais do que para pensar a lógica interna de seus distintos territórios, podemos afirmar com segurança que as proposiçóes pioneiras de Ciro Cardoso estão na gênese dessas novas abordagens. (Carla Almeida)

Os trabalhos de Ciro Cardoso sobre história agrária e da escravidão foram, quase todos, publicados nos anos de 1970 e 1980. Apesar disto, percebe-se ainda a marca de algu- 
mas questóes levantadas por ele nos trabalhos mais recentes, como os temas da "brecha camponesa" e do protagonismo dos escravos na sociedade colonial e oitocentista. ${ }^{3}$ É de se notar que, não obstante o imenso volume e a qualidade da produção historiográfica sobre as relaçóes escravistas e, mais recentemente, sobre o período pós-abolição, o texto continua bastante referido, sobretudo em trabalhos sobre a presença de um campesinato egresso do cativeiro, bem como nos estudos acerca de quilombos e quilombolas.

Não há dúvidas que a tradição historiográfica iniciada pelas obras de Ciro Cardoso e de Maria Yedda Linhares, há cerca de quarenta anos, continua a produzir trabalhos em diversos recantos do Brasil. Do ponto de vista metodológico, destaca-se a valorização de preciosas coleçóes documentais até então pouco exploradas e um olhar regionalizado. Nesse sentido, importantes reflexôes metodológicas estavam, sobretudo, em Agricultura, escravidão e capitalismo. ${ }^{4}$

A partir dessa tradição, hoje, sabemos muito mais sobre a complexidade das realidades socioeconômicas de diferentes regióes do Brasil. Entre outras áreas, poderíamos destacar os trabalhos sobre Minas Gerais e sobre o Rio Grande do Sul, localizados, especialmente, entre meados do século XVIII e do século XIX. No caso de Minas, uma forte tradição de história econômica regional foi ao encontro das preocupaçóes relativas ao estudo dos circuitos de acumulação internos e às relaçóes escravistas como ponto nodal do estudo das plantations, mas também de outras esferas produtivas. No caso do Rio Grande do Sul, soma-se, ainda, o diálogo com a fecunda história agrária platina das décadas de 1980 e 1990.

Não há como negar que muito se avançou nesse tipo de estudo. Outras formas de abordagem, francamente fora do espectro dos estudos de Ciro Cardoso, vêm sendo incorporados e, por vezes, colocadas em diálogo crítico com o modelo consagrado de pensar a história agrária e das relações de trabalho. Nesses trabalhos, em conjunto com construção e análise de séries estatísticas ou prescindindo delas, apareceram procedimentos como análises de trajetórias, estratégias e redes de relaçôes. E, de outra parte, estudos de experiências sociais, conflitos e tensóes a partir de um ponto de vista mais qualitativo.

Porém, mesmo assim, é difícil negar uma influência teórica de base, na maioria dessas obras, da chamada de atenção para as relaçóes internas da América portuguesa feita por Cardoso. 5 Com isto, os estudantes de história começaram a ir cada vez mais aos arquivos, porém, não tanto mais para referendar a tese do grande canavial, mas para testar hipóteses e com isto descobrir uma sociedade ainda hoje muito pouco conhecida: a América lusa dos

\footnotetext{
${ }^{3}$ CARDOSO, Ciro Flamarion Santana. Escravo ou camponês? O proto-campesinato negro nas Américas. São Paulo: Brasiliense, 1987. Um debate interessante sobre a obra está em: SLENES, Robert. Na senzala uma flor: esperanças e recordações na formação da família escrava. Rio de Janeiro: Nova Fronteira, 1999.

${ }^{4}$ CARDOSO, Ciro Flamarion. Agricultura, escravidão e capitalismo. Petrópolis: Vozes, 1979.

${ }_{5}^{5}$ Especialmente os textos: CARDOSO, Ciro Flamarion. Agricultura, escravidão e capitalismo. Petrópolis: Vozes, 1979. CARDOSO, Ciro Flamarion. As concepçóes acerca do "sistema econômico mundial" e do "antigo sistema colonial": a preocupação obsessiva com a "extração do excedente". In: LAPA, José (Org.). Modos de produção e realidade brasileira. Petrópolis: Vozes, 1980.
} 


\section{séculos XVI ao XVIII. (Luís Augusto Farinatti)}

* Doutor em história pela Universidade Federal Fluminense, professor titular da Universidade Federal do Rio de Janeiro, bolsista de produtividade científica do CNPq, nível 1. Rio de Janeiro, RJ, Brasil. E-mail: jl.fragoso@uol.com.br.

${ }^{* *}$ Doutora em história pela Universidade Federal Fluminense, professora associada da Universidade Federal de Juiz de Fora, bolsista de produtividade científica do CNPQ, nível 2. Juiz de Fora, MG, Brasil. E-mail: carlamca@uol.com.br.

${ }^{* * *}$ Doutor em história pela Universidade Federal do Rio de Janeiro, professor adjunto da Universidade Federal de Santa Maria. Santa Maria, RS, Brasil. E-mail: lafarinatti@gmail.com. 